\section{PLURALISMO RELIGIOSO Y EDUCACIÓN}

\author{
Celeste Jiménez de Madariaga \\ Profesora Titular de Antropología Social \\ Universidad de Huelva, Facultad de Humanidades \\ Avda. de las Fuerzas Armadas s/n, 21027 Huelva
} celeste@uhu.es

\begin{abstract}
The Spanish Constitution (1978) and Law of Religious Freedom (1980) open the possibility of religious pluralism in Spain, a possibility that in principle will stagnate within the framework legislative without a projection in the social practice. The passage towards the exercise of the religious plurality, its institutionalization, is intensifying in the last years as result of the diversification of the religions and the increase foreign immigration. In this paper, the author dwells to analyze how religious pluralism in the Spanish educative scope is being fitted. She shows the problems that consider when the right to the education of the religion - of the religions- it is applied in the schools where, in addition, the historical presence of the catholic religion prevails.
\end{abstract}

KEY WORDS: Religious pluralism; education; legislation and religion.

En los últimos años estamos observando importantes cambios en la sociedad española que, si bien se vinculan a procesos de transformación a escala mundial, están afectando de manera directa a la cotidianidad de las gentes. La creciente globalización económica y del mercado, el aumento de los flujos migratorios internacionales, la expansión de las nuevas tecnologías y sistemas de comunicación, la aceleración de los avances científicos y el acceso generalizado a estos avances por parte de los individuos, han impulsado una nueva situación social caracterizada por la multiculturalidad y el mestizaje. Nuestras sociedades se hacen cada vez más heterogéneas y plurales, no solo por el movimiento de gentes (en otros momentos de la historia han habido desplazamientos migratorios de gran trascendencia) sino por la vertiginosa circulación de ideas e información, de manera que se multiplican las adhesiones y conversiones a corrientes de pensamiento originariamente distantes. La diversidad no se explica exclusivamente por causas exógenas -aunque su incidencia sea notoria- sino que se genera internamente bajo dos paradigmas: por un lado, la libertad y el derecho de elección y, por otro lado, la ruptura con

\section{RELIGIOUS PLURALISM AND EDUCATION}

RESUMEN: La Constitución Española (1978) y Ley de Libertad Religiosa (1980) abren la posibilidad del pluralismo religioso en España, una posibilidad que en principio se estancará en el marco legislativo sin una proyección en la práctica social. El paso hacia el ejercicio de la pluralidad religiosa, su institucionalización, se está intensificando en los últimos años a raíz de la diversificación de las religiones y el aumento de inmigración extranjera. En este artículo, la autora se detiene a analizar cómo se está encajando el pluralismo religioso en el ámbito educativo español. Muestra los problemas que se plantean cuando el derecho a la enseñanza de la religión -de las religiones- se aplica en las escuelas donde, además, prevalece la histórica presencia de la religión católica.

PALABRAS CLAVE: Pluralismo religioso; educación; legislación y religión.

los antiguos esquemas que defendian la homogeneidad y el monoculturalismo como valor cultural. La cercanía de lo diverso impone que los distintos grupos y personas tengan que interactuar necesariamente; es la "convivencia entre culturas" que no siempre sucede de manera dialógica, sino con enfrentamientos en ocasiones muy beligerantes, lo que según algunos analistas supone un problemático "choque de civilizaciones" (S. Huntington, 2005).

En este escenario, las religiones siguen ocupando un lugar destacado. En contra de los que pronosticaban la decadencia de la religión en la modernidad, con la denominada "teoría de la secularización", estamos presenciando una revitalización generalizada del universo religioso, ahora bien, redefinido bajo renovadas y múltiples interpretaciones. La globalización, como fenómeno integral, actúa asimismo en las religiones facilitando la deslocalización de éstas y la publicitación de creencias y prácticas religiosas. Lejos de quedar relegada al ámbito privado y doméstico, entramos en el tiempo de las religiones mediáticas. Junto a la diversificación interna y la internacionalización de 
la Iglesia Católica, la vorágine expansionista se aprecia especialmente en los dos movimientos religiosos más dinámicos del mundo contemporáneo: el Islam renaciente y el protestantismo popular, principalmente en su vertiente pentecostal (P. Berger, 2005, 6).

En España este proceso de cambio global adquiere sus propias connotaciones. En pocas décadas ha habido una rápida transformación hacia un estado democrático, con posibilidad de ejercer la "diferencia", incluyendo las libertades religiosas, abriéndose la oportunidad de conocer y acceder a otros credos y formas de pensamiento. Al mismo tiempo, nos convertimos en territorio de inmigración con la masiva y acelerada entrada de inmigrantes de muy diversa procedencia: Europa del Este, Magreb, África Subsahariana, y América del Centro y Sur'.

Con todo, la sociedad española está experimentando un reajuste para adaptarse a la nueva realidad social, donde conviven españoles autóctonos, nuevos españoles -inmigrantes nacionalizados e hijos de inmigrantes nacidos en España- e inmigrantes en otras condiciones legales 0 irregulares. La adaptación implica el reconocimiento de la diversidad cultural incluyendo el pluralismo religioso con la coexistencia del laicismo y el agnosticismo, la supremacía del catolicismo enraizado en la tradición histórica española, la aparición de nuevos movimientos religiosos católicos, y el afloramiento y aparición de otras religiones no católicas.

Ante esta naciente situación de pluralidad de ideas y religiones, muchos factores podrían ser objeto de análisis, todos ellos de forma interrelacionada. Pero en esta ocasión, nos detendremos a analizar cómo se está encajando el pluralismo religioso en uno de los ejes medulares de la articulación social: la educación. La presencia de la religión en el ámbito educativo institucional español ha tenido y tiene un peso muy importante, pero con un único apellido: el catolicismo. Podemos decir que históricamente la Iglesia Católica ha sido un poderoso soporte y patrocinio de la educación en España; su influencia se ha extendido no solo en las escuelas de su titularidad sino también en las escuelas públicas. El orden establecido durante décadas parece modificarse ante la expansión del laicismo y/o la posibilidad de incorporación en el espacio educativo de otras religiones. Así, la enseñanza de las religiones minoritarias ${ }^{2}$ tiende a moverse entre tres tramas aparen- temente complementarias (al menos en la correspondencia causa-efecto), pero que puestas en juego se tornan dicotómicas:

1. La declaración de "aconfesionalidad" del estado democrático español.

2. El derecho a la libertad religiosa y, consecuentemente, la aceptación del pluralismo religioso.

3. El derecho a la enseñanza, incluida la enseñanza de las diversas religiones.

Uniendo pluralismo religioso, educación e inmigración, se ha extendido una percepción problemática del hecho, que está dando lugar a toda una serie de reflexiones y propuestas teóricas y empíricas en torno a cómo afrontar la religión -las religiones- en la enseñanza formal, con la dificultad de conciliar las diferencias entre grupos culturales y religiosos heterogéneos.

\section{LA ILUSORIA SEPARACIÓN ENTRE ESTAdO Y RELIGIÓN}

Durante décadas, los españoles han sido testigos -nunca inertes- de una placentera comunión entre los poderes civiles, encabezados por la omnipresente figura de Francisco Franco, y los poderes de la Iglesia Católica. En España solo era posible practicar una religión, más aún todos los españoles tenían que reconocer la religión católica. La confesionalidad católica del Estado impedia cualquier presencia de confesiones religiosas no católicas, al menos públicamente. Tal y como determinaba el artículo 6 del Fuero de los Españoles ${ }^{3}$ : "La profesión y práctica de la religión católica, que es la del Estado español, gozará de protección oficial. Nadie será molestado por sus creencias religiosas ni el ejercicio privado de su culto. No se permitirán otras ceremonias ni manifestaciones externas que las de la religión católica". Evidentemente, esta prohibición de manifestación pública de otras religiones no católicas afectaba a todos los campos sociales, incluido la educación. Únicamente en los últimos años de la Dictadura, la situación se suaviza con la Ley de Libertad Religiosa 44/1967, de 28 de junio, que, entre otras cuestiones, eximía a los alumnos de recibir enseñanza religiosa católica en las escuelas públicas, aunque no introducía la posibilidad de enseñanza religiosa no católica. 
Con la paulatina llegada de la Democracia, se inicia un proceso de desvinculación entre el Estado y la Iglesia Católica, que con altibajos aún perdura. Las mayores dificultades se basan en que la influencia del catolicismo se extiende mucho más allá del escenario puramente religioso; pensemos en la importante y secular presencia de la Iglesia en todos los ámbitos de la esfera política, económica, social y cultural. Entidades financieras, instituciones de enseñanza, organismos asistenciales y culturales, fundaciones benéficas y hospitales, etc., son directa o indirectamente dependientes de la Iglesia Católica, lo que supone un peso poderoso en la articulación sociopolítica de España.

La Constitución de 1978 proporcionará una imagen del estado español aconfesional, imagen que será una apariencia ilusoria en una sociedad cambiante. Este hecho se enmarca dentro de un proceso generalizado de tolerancia, igualdad y no discriminación por razones de religión que aparece en las distintas constituciones nacionales europeas, fundamentalmente en aquellos paises más afectados por la inmigración y la multiculturalidad que conlleva ${ }^{4}$. La estrategia más comúnmente practicada en los paises europeos ha sido relegar la religión a la esfera individual, como una cuestión personal donde el Estado no debe intervenir. El tema religioso se intenta mantener al margen del ejercicio político, incluida la dimensión educativa. Por otro lado, además, se utiliza la maniobra de vincular el pluralismo religioso exclusivamente a la inmigración, con el fin de mostrarlo como una problemática más de la integración inmigratoria.

En España, los mayores inconvenientes se derivan del referido dominio de la Iglesia Católica y su histórica alianza con el poder político establecido. Llegado el momento, las dificultades para el divorcio Estado-Iglesia han sido muy profundas. Una vez iniciado el proceso de democratización, ya en el año 1980, se promulga la Ley de Libertad Religiosa, que pretende ser el reflejo de la declaración de aconfesionalidad del Estado. Esta ley abre la posibilidad de pluralismo religioso en España, una posibilidad que en principio se estancará en el marco legislativo sin que por ello tuviera una proyección en la práctica social. El paso hacia el ejercicio de la pluralidad religiosa se ha intensificado (se está intensificando, más bien) en los últimos años a raíz de la globalización de las religiones y su deslocalización, la expansión mediática y la facilidad de acceso de los individuos a cualquier credo religioso, y el aumento de la inmigración extranjera en España ${ }^{5}$ (J. J. Tamayo, 2007). Es entonces cuando la presencia de "otras" religiones no católicas se hace más visible, y es entonces cuando el derecho a ejercer el pluralismo religioso se problematiza, teniendo en cuenta, además, la permanencia de la religión en la mayoría de los ámbitos de la vida social individual y colectiva, entre otros, la educación.

La enseñanza de la religión constituye uno de los derechos fundamentales de los españoles, tanto en la esfera doméstica, en las instituciones religiosas, como en la escuela. Hasta ahora, con el dominio de la Iglesia Católica, poco se había cuestionado este derecho. Pero, en una sociedad cada vez más plural, la interacción educación-religión está sometida a revisión y ha entrado en fuerte debate. A grandes rasgos, la polémica se mueve entre varias posturas contrapuestas: por un lado, la defensa de la enseñanza de la religión en la escuela, habida cuenta del dominio de la religión católica en el escenario educativo; por otro lado, los que abogan por un laicismo a ultranza donde la religión no tiene cabida ni en la escuela ni en ningún otro espacio social; $y$, por último, una postura de no confesionalidad a la par que se admite el derecho a la enseñanza de las religiones, ahora bien con el tratamiento igualitario de todas ellas.

Ciertamente un estado aconfesional se presupone no vinculado a ninguna confesión religiosa, en tal caso ise debería ofertar la enseñanza de la religión en las escuelas públicas?, y en caso afirmativo, ¿qué religiones? Y los colegios concertados vinculados a la Iglesia Católica que poseen financiación pública ¿deberían ofertar la enseñanza de otras religiones? La problemática se hunde, además, en la complejidad del sistema educativo que tenemos en España en el que coexisten escuelas privadas y públicas junto con ese híbrido al que se ha denominado concertadas; al mismo tiempo que la sociedad actual delega cada vez más la responsabilidad de una adecuada educación de nuestros hijos a las instituciones educativas. A todo se añade la descentralización de la educación por la transferencia de estas competencias a las comunidades autónomas.

La clave se centra en definir qué modelo educativo corresponde al prototipo de Estado que estamos construyendo, a la vez que concretar sin fisuras qué postura van a tomar los gestores políticos ante el pluralismo religioso. Desde luego, 
lo menos adecuado es obviar la realidad: la existencia de un espectro multireligioso y la necesidad de dar respuestas a la problemática educativa de la religión. Aunque haya quienes pretendan excluir la religión de la esfera pública, el pluralismo religioso tiene densas implicaciones institucionales por lo que se hace imprescindible que los legisladores permitan el juego creativo de ese pluralismo, aún sabiendo que se originarán conflictos en el campo religioso y educativo, y tendrá importantes repercusiones en las dinámicas de la integración y la estabilidad social. Cualquier posible solución pasa por seguir vinculando Estado y Religión, pero con un trascendental cambio: su enunciación en plural; es por ello que cualquier posible solución pasa por el diálogo entre religiones, y entre éstas y las instituciones políticas.

\section{El DERECHO A UNA ENSEÑANZA RELIGIOSA PLURAL}

A nivel general, la legislación sobre pluralismo religioso es bastante desconocida. La mayoría de la gente ignora sus derechos en relación a las creencias y prácticas religiosas, incluidas las cuestiones educativas, y desconocen la jurisprudencia en torno al pluralismo religioso.

En el marco jurídico actual, la educación religiosa es uno de los derechos fundamentales constitucionales en tanto se proclama explícitamente en la Constitución Española de 1978, concretamente en el artículo 27.3: "Los poderes públicos garantizarán el derecho que asiste a los padres para que sus hijos reciban formación religiosa y moral que esté de acuerdo con sus propias convicciones religiosas". Este derecho de los padres deriva a su vez del derecho de libertad religiosa recogido asimismo en la Constitución (art. 16.1).

El desarrollo de estos derechos constituciones, el derecho a la educación religiosa como una de las manifestaciones del derecho a la libertad religiosa, se explicita ya desde el año 1980 en la citada Ley Orgánica 7/1980, de Libertad Religiosa (LOLR). El artículo 2.1.c) de esta Ley, garantiza que toda persona pueda "recibir e impartir enseñanza e información religiosa de toda índole, ya sea oralmente, por escrito o por cualquier otro procedimiento; elegir para sí, y para los menores no emancipados e incapacitados, bajo su dependencia, dentro y fuera del ámbito escolar, la educación religiosa y moral que esté de acuerdo con sus propias convicciones".
Así pues, la enseñanza de la religión en los centros docentes es, por ley, un derecho incuestionable. La misma Ley de Libertad Religiosa (art. 2.3) expone que: "Para la aplicación real y efectiva de estos derechos [los derivados de la libertad religiosa], los poderes públicos adoptarán las medidas necesarias para facilitar (...) la formación religiosa en los centros docentes públicos". Ahora bien, al poner en práctica este derecho nos enfrentamos a una triple problemática ante la falta de precisión jurídica y las dificultades en la práctica de la gestión administrativa:

- La enseñanza religiosa en los centros docentes, ¿contradice la aconfesionalidad del Estado Español y, consecuentemente, de los ciudadanos que opten por esta aconfesionalidad?

- Dada la libertad de elección de la enseñanza religiosa y, asimismo, de la religión a elegir, ¿se debe integrar esta enseñanza en los planes docentes y currículos?

- Si la enseñanza debe ser "... de acuerdo con sus propias convicciones religiosas" y "... de toda índole", ¿cómo posibilitar la pluralidad de religiones en la escuela?

Sobre la primera cuestión, el principio de la no confesionalidad del Estado español aparece enunciado en el art. 16 de la Constitución. Una de las consecuencias de este principio en el ámbito educativo es la neutralidad ideológica de los centros docentes públicos. Esta neutralidad no es un precepto opuesto al derecho a la educación religiosa ni imposibilita que en los centros docentes se imparta enseñanzas con una orientación ideológica determinada, siempre que estas actividades formativas tengan un carácter voluntario para los alumnos (M. Rodríguez Blanco, $2005,1)$. Para dirimir dudas sobre esta cuestión concreta, el Tribunal Constitucional emitió un obiter dictum de la Sentencia 5/1981, de 13 de febrero ${ }^{6}$ :

"En un sistema jurídico político basado en el pluralismo, la libertad ideológica y religiosa de los individuos y la confesionalidad del Estado, todas las instituciones públicas y muy especialmente los centros docentes, han de ser, en efecto, neutrales. Esta neutralidad, que no impide la organización en los centros públicos de enseñanzas de seguimiento libre para hacer posible el derecho de los padres a elegir para sus hijos la formación religiosa y moral que esté de acuerdo con sus propias convicciones (art. 37.3 de la Constitución), es una característica 
necesaria de cada uno de los puestos docentes integrados en el centro, y no el hipotético resultado de la casual coincidencia en el mismo centro y frente a los mismos alumnos, de profesores de distinta orientación ideológica cuyas enseñanzas se neutralicen recíprocamente" (Fundamento Jurídico 9.).

Por lo tanto, la legislación avala las enseñanzas de contenido religioso en los centros docentes públicos y la constitucionalidad de estas enseñanzas es incuestionable. Únicamente existen dos requisitos indispensables para su puesta en práctica: la voluntariedad y que estas enseñanzas se desarrollen teniendo en cuenta los principios democráticos de convivencia y los derechos y libertades fundamentales (art. 7.2 de la Constitución).

El primero de los requisitos, la libertad de los padres en la elección de enseñanza religiosa, parece que está garantizado a priori, al menos en los centros públicos: la formación religiosa se concibe como una oferta obligatoria para los centros y de carácter voluntario para los alumnos. Pero incluso este derecho tan básico de libre elección tiene sus objeciones. Una de ella se relaciona con la misma estructura del sistema educativo en España, pues si bien la libertad de elección de enseñanza religiosa en los centros públicos está asegurada institucionalmente, este mismo ejercicio en los centros concertados de titularidad religiosa -católica, en su práctica totalidad- se relativiza, aunque formalmente la imagen que ofrezcan ante la Administración sea de atender y aprobar la voluntad de los padres. Ciertamente la libertad de elección puede ser previa: optar por inscribir a los hijos en centros públicos o en los escasos concertados no religiosos. Pero esto puede ser entendido como una situación de desigualdad al disminuir las opciones en la elección de centros docentes, con una clara desventaja frente a los padres de adscripción católica que optan a un mayor número de centros, teniendo en cuenta, además, la financiación pública de los centros concertados.

La verificación del segundo requisito, que las enseñanzas de contenido religioso respeten los principios democráticos de convivencia y los derechos y libertades fundamentales, es realmente complicada tanto por la imprecisión de los contenidos como por las dificultades que supone su comprobación. En efecto, toda enseñanza -no solo la de contenido religioso- debe respetar la legislación vigente en el estado español y los derechos y libertades que en ella se explicitan. Sin embargo, los límites entre la "ética de estado", elaborada institucionalmente, y las ideas, valores y creencias de las gentes pueden llegar a ser muy imprecisos. Los valores son construcciones culturales y como tales están sujetos a interpretación. Aunque se revisen los contenidos temáticos de las enseñanzas religiosas y se publiquen los currículos -cosa que es obligatoria-, la comprobación de que esos contenidos se ofrecen adecuadamente resulta en verdad complicada, más aún cuando la designación de los docentes que imparten estas materias no corresponde a las administraciones públicas sino que dependen directamente de las instituciones religiosas.

Los dos requisitos argumentados enlazan con la segunda de las problemáticas planteadas, es decir, si dada la libertad de elección de la enseñanza religiosa y, asimismo, de la religión a elegir, se debe integrar o no estas enseñanzas en los planes docentes y currículos. El tema ha suscitado una controvertida polémica que, además, se ha extendido entre los distintos ámbitos de opinión. Desde el ámbito jurídico existen discrepancias sobre si en la legislación española se contempla la obligatoriedad de incluir la religión como una asignatura equiparable al resto de materias de los programas formativos, en los diferentes niveles educativos. La polémica se puede simplificar en dos posturas contrapuestas que responden a dos maneras de interpretar el señalado artículo 27.3 de la Constitución ${ }^{7}$ : aquellos que lo interpretan como una exigencia de impartir formación religiosa en los centros docentes y, consecuentemente, en las mismas condiciones que el resto de materias temáticas; $y$, aquellos otros que consideran incorrecto interpretarlo en el sentido de que los poderes públicos están obligados a incluir la enseñanza de la religión en los programas formativos de la escuela. Los tratados y declaraciones vigentes en el marco internacional sobre derechos humanos recogen el derecho a la educación religiosa pero no impone a los estados la obligación de incluir la enseñanza de la religión en los programas formativos de la escuela pública ${ }^{8}$.

La imprecisión legislativa española y la ausencia de pronunciamientos firmes, tanto por parte del Tribunal Constitucional como por parte del Tribunal Supremo, producen un vacio normativo que ha sido manipulado por los distintos gobiernos habidos durante la etapa democrática, con sucesivas reformas del sistema educativo (LOGSE, LOCE, LOE). No podemos, por tanto, fijar conclusiones a nivel normativo sobre la inclusión de la enseñanza religiosa en los currículos, depende de las interpretaciones que se formulen. Pero

ARBOR Vol. 187749 mayo-junio [2011] 617-626 ISSN: 0210-1963 
aún admitiendo su inclusión, queda por establecer posibles alternativas curriculares para los alumnos cuyos padres reclamen el derecho a no recibir enseñanza religiosa, y, todavía más, si deben existir estas alternativas ya que, como señala el Tribunal Supremo", la "misma existencia es una mera consecuencia del reconocimiento de aquella garantía, de modo que es evidente que las actividades alternativas no sería necesario programarlas si no fuese preciso que los poderes públicos estuvieran obligados constitucionalmente $a$ atender a la enseñanza religiosa...". Algunas alternativas se han probado ya, como los cursos de "ética y moral" para el Bachillerato y Formación Profesional ${ }^{10}$ y la asignatura de "Sociedad, cultura y religión" para la Educación Secundaria Obligatoria y primer curso de Bachillerato ${ }^{11}$, pero aún es un asunto en discusión. El debate se centra en la propuesta de incluir la religión entre los contenidos educativos pero con carácter no confesional, de manera que se contemple el fenómeno religioso desde la perspectiva cultural e histórica. La actual Ley Orgánica de la Educación (BOE n. ${ }^{\circ} 106$, de 4-5-2006) no ofrece posibles soluciones, más aún, aborda el tema de la "enseñanza de la religión" y del "profesorado de religión" en disposiciones adicionales (segunda y tercera, respectivamente), manteniendo las deficiencias sistémicas ya existentes. La polémica se ha incrementado recientemente con la implantación en el curso académico 2007/2008 de la asignatura "Educación para la ciudadanía", una asignatura que desde diversos sectores de la sociedad española es calificada como un adoctrinamiento de estado mientras que sus partidarios la defienden por los valores democráticos y convivenciales que puede aportar a los alumnos. En cualquier caso, no es una asignatura que se ofrezca como alternativa a la religión, sino que es de carácter obligatorio con independencia de la opción de una educación religiosa o no elegida por los padres. Por lo tanto, el problema no solo permanece, sino que se extiende.

La toma de decisiones sobre el tema de la religión y el currículo se complica si tenemos en cuenta que la presencia de la asignatura de una concreta religión, la católica, en los programas formativos preuniversitarios está pactada normativamente, y en condiciones equiparables a las demás disciplinas fundamentales. Así se establece desde el Acuerdo sobre Enseñanza y Asuntos Culturales firmado con la Santa Sede en el año 1979. Este Acuerdo reglamenta la obligatoriedad de ofertar enseñanza religiosa católica en la escuela, articulando al menos tres de las condiciones en las que se establecerá: su inclusión en los planes de estudio del sistema educativo español; el régimen y designación del profesorado por parte del Ordinario Diocesano; y, la concesión a la jerarquía eclesiástica católica de las atribuciones sobre los contenidos, libros de texto y material didáctico de esta enseñaza. Es necesario precisar que el Acuerdo tiene naturaleza jurídica concordatoria y, en consecuencia, se designa como un tratado internacional entre el Estado Español y la Santa Sede, y como tal sus disposiciones solo podrán ser derogadas o modificadas bilateralmente según las normas generales del Derecho Internacional.

Ante estos privilegios que goza la Iglesia Católica, nos replanteamos la última de las problemáticas suscitadas: cómo hacer efectivo el derecho al pluralismo religioso en la escuela. Las tramitaciones para integrar las religiones minoritarias en el sistema educativo español han sido lentas y poco efectivas, aunque los inicios fueron muy fructíferos. Una vez aprobada la Constitución de 1978, se reconocía el ejercicio del pluralismo religioso con la Ley Orgánica de Libertad Religiosa, publicada el 5 de julio de 1980. Solo unos días después, el 16 de julio de 1980, se dictaron dos Órdenes Ministeriales que reglamentaban disposiciones relativas a la enseñanza de la religión no católica en cada uno de los niveles educativos preuniversitarios (que entonces eran Educación Preescolar, Educación General Básica, Bachillerato y Formación Profesional). Con ello se pretendía dar un trato similar a todas las confesiones religiosas, incluyéndolas por igual en los planes educativos, y actuando con las religiones minoritarias del mismo modo que con la religión católica, o sea, según el modelo establecido con la Santa Sede en el Acuerdo sobre Enseñanza y Asuntos Culturales. En los años posteriores se llegaron a publicar algunas disposiciones reglamentarias sobre el contenido de las enseñanzas de algunas confesiones religiosas en los distintos niveles educativos: Programa de Enseñanza Religiosa Judia ${ }^{12}$, Programa de Enseñanza Religiosa Adventista ${ }^{13}$, y Programa de Enseñanza Religiosa de la Iglesia de Jesucristo de los Santos de los Últimos Días ${ }^{14}$. No obstante, estas disposiciones tuvieron poca repercusión y escasa aplicación real.

Este modelo de sistema educativo, tan aperturista hacia el pluralismo religioso, que se planteó en los primeros años de la Democracia bajo la legislatura de la Unión de Centro Democrático, cambiará posteriormente y hasta la actualidad. Desde la LOGSE, en 1990, a nuestros días, los mecanismos utilizados para garantizar la pluralidad de la enseñanza de las 
religiones, tal y como determinan las leyes, han sido y son más restrictivos: solo se admiten aquellas confesiones religiosas que hayan suscrito Acuerdos de Cooperación con el Estado español. Esta política legislativa aparta a las religiones que, por distintos motivos, no tengan convenio $y_{\text {, además, fuerza }}$ a las confesiones religiosas no católicas a burocratizarse, siguiendo un largo y tedioso procedimiento administrativo que se extiende desde su reconocimiento como entidad juridica al registro y la obtención de distintas concesiones. Veámoslo con más detenimiento, pero sin duda todo este procedimiento proporciona a los poderes ejecutivos un mayor control sobre las minorias religiosas y dilata en el tiempo decisiones sobre la enseñanza de determinadas religiones en la escuela. Paradójicamente, estas restricciones han coincidido con los inicios del proceso inmigratorio en España y el aumento de alumnos extranjeros en los centros educativos y de la solicitud de enseñanzas de religiones no católicas.

Como decíamos, únicamente se ofrecerá enseñanza de religiones no católicas en los centros públicos si han firmado Acuerdos con el Estado español. Para ello, el procedimiento es el siguiente. Los seguidores de las confesiones religiosas han tenido que previamente organizarse en "entidades religiosas", registrarse como tales en el Registro de Entidades Religiosas dependiente del Ministerio de Justicia ${ }^{15}$. Las entidades registradas tendrán que agruparse en federaciones asimismo registradas y cuyos órganos representativos actuarán como intermediarios con el Estado. Otro importante paso previo a la firma de cualquier acuerdo es la obtención de la categoría de "notorio arraigo". Una Comisión Asesora tiene la competencia de decidir qué entidades federadas "por su ámbito y número de creyentes hayan alcanzado notorio arraigo en España". Tener la declaración de "notorio arraigo" supone una condición indispensable para poder establecer Acuerdos o Convenios de Cooperación donde se fijen los derechos en materia religiosa, incluido el derecho a la enseñanza de esa religión en concreto.

Hasta hace muy poco tiempo, sólo la religión islámica, la israelita (como se autodenominaron los judíos) y las evangélicas habían sido reconocidas como "confesiones de notorio arraigo", siendo muy recientemente incluidos también la Iglesia de Jesucristo de los Santos de los Últimos Días (Mormones) y los Testigos Cristianos de Jehová. Pero, por el momento, únicamente se han firmado Acuerdos de Cooperación con las tres primeras minorias religiosas reconocidas, los tres simultáneamente en el año 1992: con la Federación de Entidades Religiosas Evangélicas de España (FEREDE), con la Federación de Comunidades Israelitas de España (FCIE), y con la Comisión Islámica de España (CIE) ${ }^{16}$. Es decir, en el Estado español, se concede el derecho a la enseñanza en la escuela exclusivamente de estas tres religiones minoritarias. De hecho, actualmente, cuando los niños se matriculan en un colegio público, se pregunta a los padres mediante un cuestionario sobre la opción voluntaria de recibir enseñanza religiosa ${ }^{17}$, y se muestran las cuatro posibilidades a elegir correspondientes a las cuatro confesiones reconocidas (católica, evangélica, islámica o judaica). Si bien, en la realidad, las posibilidades de elección se reducen a un puro formalismo ante las limitaciones existentes al poner en práctica las enseñanzas de las religiones minoritarias en los colegios.

Si bien los Acuerdos de Cooperación con las Confesiones Religiosas de Notorio Arraigo llevan firmados desde el año 1992, el hecho de existir la "firma" no ha supuesto una posterior aplicación efectiva de ellos, ni en todos sus puntos, ni de forma similar para todas las religiones en las distintas Comunidades Autónomas ${ }^{18}$. En los tres Acuerdos se dedica el artículo 10 para establecer explícitamente el derecho a recibir la enseñanza de la religión en los centros educativos públicos, concertados y privados en todos los niveles preuniversitarios. También se establecen las competencias de las respectivas Entidades Religiosas en relación a la designación de los profesores, el contenido de los currículos y los materiales de estudio.

Para hacer más objetivos estos Acuerdos en materia educativa, se desarrollan y completan posteriormente con el "Real Decreto 2438/1994, de 16 de diciembre, por el que se regula la enseñanza de la religión, así como por los Convenios específicos que se acuerdan con los representantes y federaciones de las distintas entidades religiosas, como los Convenios referidos a la Designación y Régimen Económico de las Personas Encargadas de la Enseñanza Religiosa en Centros de Educación".

Aunque aparentemente el marco normativo para llevar a la práctica la enseñanza del pluralismo religioso en España está bastante elaborado, su aplicación se enfrenta a dos importantes obstáculos: el primero en referencia a los procedimientos administrativos para su ejecución, y el segundo concierne a la escasez de recursos e infraestructura para llevar a la práctica estas enseñanzas en los colegios. 
El primer obstáculo compete directamente a la política y dinámica asociativa de las propias confesiones religiosas minoritarias. El Estado español únicamente trata con aquellos sujetos sociales que ejerzan como representantes de las confesiones religiosas federadas, lo cual implica un consenso entre las entidades religiosas que no siempre se $\mathrm{da}$, de hecho en casos como el Islam encontramos no solo la inexistencia de consenso sino graves enfrentamientos internos $y$, cuanto menos, dos facciones enfrentadas $y$ materializadas en dos federaciones en disputa: la Unión de Comunidades Islámicas de España (UCIDE) y la Federación de Entidades Religiosas Islámicas de España (FEERI). Esta inadecuación en los procedimientos de actuación, que deja a merced de los dirigentes religiosos de turno toda la capacidad de decisión, hace que la puesta en práctica de la enseñanza de cada religión en concreto se haya desarrollado de distinta forma en las distintas confesiones religiosas minoritarias reconocidas, con independencia de su extensión geográfica, el número de fieles o la tradición histórica en España. Así, mientras que desde el año 1996 se imparte religión evangélica en muchas escuelas de la mayor parte de las comunidades autónomas, no ocurre lo mismo con el islam que solo se ofrece oficialmente desde el curso 2005/2006 en cuatro autonomías: Andalucía, Aragón y las ciudades autónomas de Ceuta y Melilla. Igualmente, en la actualidad, la religión judía únicamente se imparte en tres centros situados en Madrid, Barcelona y Melilla.

El segundo obstáculo, la escasez de recursos e infraestructura para llevar a la práctica estas enseñanzas, se encuadra en las deficiencias generalizadas de la enseñanza en España y en cada comunidad autónoma en particular; a la vez que se deriva de la imprecisión normativa en materia de financiación y designación de docentes en la enseñanza de estas religiones. De nuevo, el peso recae en las propias federaciones de entidades religiosas minoritarias, quienes decidirán sobre el perfil de sus docentes, los contenidos curriculares de las asignaturas e incluso los textos y materiales didácticos.

\section{A MODO DE CONCLUSIÓN}

Como vemos, el pluralismo religioso en la escuela es un problema estructural inserto en el propio sistema político educativo. Las dificultades son tanto conceptuales como de procedimiento y puesta en práctica: desde las discrepancias sobre binomio religión-enseñanza pública regla$\mathrm{da}$, a las lagunas e imprecisiones legales, y a la falta de operatividad de las decisiones políticas tomadas respecto a la puesta en práctica de normativas en materia de enseñanzas de religiones minoritarias, profesorado, currículos y material didáctico. Todo ello agravado, además, por el secular dominio de la Iglesia Católica.

Por otra parte, la preocupación por la inmigración extrajera en España ha derivado hacia una ficticia visualización del pluralismo religioso a través de los inmigrantes, de manera que se vehicula el problema de la religión a las políticas de integración ocultando así la dimensión de su efecto. No obstante, esta pretendida unión, pluralismo religioso e inmigración, muestra cada vez más su inconsistencia no solo por el aumento del pluralismo religioso entre los españoles sino por el nacimiento en España de segundas y terceras generaciones de inmigrantes no católicos, y las repercusiones de las religiones mediáticas con su deslocalización territorial. Como estamos apreciando desde hace algunos años, la heterogeneidad religiosa tiende a extenderse al tiempo que se diversifica la sociedad española.

Estos profundos cambios en la sociedad, las alternancias de políticas educativas según los gobiernos habidos en el poder, una deficitaria gestión sobre pluralismo religioso, y la desviación de la religión como problema secundario de la integración de los inmigrantes, han contribuido, entre otras razones, a que carezcamos de sólidas medidas sobre las enseñanzas de las religiones en la escuela, desde el mismo planteamiento inicial de si deben o no incluirse.

La religión en la escuela o, mejor dicho, el pluralismo religioso en la escuela no parece constituir una preocupación prioritaria de los gestores de las políticas públicas. Únicamente ante conflictos puntuales, la religión deja de ser obviada como, por ejemplo, algunos conflictos ocurridos ante la presencia de símbolos religiosos en la escuela (el uso del hiyab en las niñas musulmanas) o la polémica incorporación de la asignatura de "Educación para la ciudadanía". Cuando el problema salta a los medios de comunicación, se renueva el dilema en el espacio público ante la lógica inquietud de las gentes por un tema tan fundamental como es la educación de los hijos. Entre tanto, el debate del pluralismo religioso en la escuela continúa. 
1 Los fundamentos conceptuales y etnográficos de este artículo proceden de mi participación en un amplio estudio sobre Pluralismo religioso en contextos de inmigración en Andalucía, que se realizó durante los años 2004 a 2006. El proyecto fue dirigido por D. Rafael Briones Gómez (Universidad de Granada) en el marco de las investigaciones $I+D+I$, y fue financiado por el Ministerio de Educación y Ciencia y la Consejería de Gobernación de la Junta de Andalucia. En este trabajo también participó la Dra. Sol Tarrés Chamorro a quien agradezco sus sugerencias y aportaciones que sin duda han enriquecido este escrito.

2 Entendemos este término, "religiones minoritarias", no solo desde la óptica cuantitativa en contraste con el elevado número de cristianos católicos, sino también desde la perspectiva del dominio ejercido por los católicos en España, un dominio que se remonta históricamente pero que se mantiene en la actualidad. No obstante, advertimos ya del vertiginoso aumento de miembros de religiones no católicas en España, de manera que podemos reinterpretar el dominio en "dominios" (de ello trataremos más adelante).

3 En su redacción originaria de 17 de julio de 1945.

4 Proceso que se remonta a la Declaración Universal de los Derechos del Hombre formulada por la ONU en 1948 cuando reconocía, en el art. 18, el derecho a la libertad de religión, incluyendo la enseñanza, el culto y las prácticas tanto individuales como colectivas, tanto públicas como privadas.

Recibido: 10 de junio de 2009

Aceptado: 10 de enero de 2010 las religiones en el mundo actual se debe a un vacío existencial -0 espiritual según se interprete- tras la crisis de las ideologías, tanto de tinte comunista como capitalista, y las utopías solidarias. Los nuevos movimientos religiosos, ya sean de reciente creación o escisiones metamorfoseadas de antiguas confesiones, vienen a cubrir ese vacío.

6 Igualmente recogido por M. Rodriguez Blanco (2005: 1) para argumentar la no contradicción entre la neutralidad ideológica de los centros docentes públicos y la enseñanza de las religiones.

7 Sobre los debates jurídicos en torno a la obligatoriedad de la enseñanza de la religión en la escuela suscitados a raíz de la interpretación de la Constitución Española se puede consultar el texto de R. M. Satorras, La libertad de enseñanza en la Constitución Española (1998).

8 Por ejemplo, en el Pacto Internacional de Derechos Civiles y Políticos (1966) adoptado por el Comité de Derechos Humanos en 1993, Pacto Internacional de Derechos Económicos, Sociales y Culturales (1966), Convenio Europeo de Derechos Humanos (1950), y la Carta de los Derechos Fundamentales de la Unión Europea (2000).

9 Sentencia del Tribunal Supremo de 30 de junio de 1997 (RJ 597).

10 Según Orden Ministerial de 16 de julio de 1980.

11 Según el artículo 2.3 la Orden Ministerial de 3 de agosto de 1995.

12 Orden de 9 de abril de 1981 para los niveles de Educación Preescolar y EGB.

13 Orden de 1 de julio de 1983 para los niveles de Educación Preescolar y EGB, y Orden de 7 de noviembre de 1983 para el nivel de BachiIlerato. 
14 Orden de 19 de junio de 1984 para los niveles de Bachillerato y Formación Profesional, y Orden de 22 de noviembre de 1985 para el nivel de EGB.

15 Por el Real Decreto 142/1981, se crea el Registro de Entidades Religiosas que regula los procedimientos jurídicos y administrativos para reconocer la personalidad jurídica de todas aquellas entidades que se inscriban en él, diferenciando entre Iglesia Católica, Minorías Religiosas y Fundaciones. El funcionamiento de este Registro se regula a través de la Orden 1375/2002, determinando la organización y competencias de una Comisión Asesora, creada y regulada legalmente en 1983.

16 Por el mismo orden: Ley 24/1992, de 10 de noviembre; Ley 25/1992, de 10 de noviembre; y Ley 26/1992, de 10 de noviembre.

17 Algunos juristas consideran esta práctica anticonstitucional. El artículo 16.2 de la Constitución dice que nadie podrá ser obligado a declarar sobre su ideología, religión o creencias. Sin embargo, los padres o tutores tienen que declarar sus convicciones al manifestar su deseo de que sus hijos reciban enseñanza religiosa.
18 Hay que tener en cuenta el amplio traspaso de competencias existente entre el gobierno central y muchos de los gobiernos autonómicos, sobre todo respecto a materia de educación y cultura.

\section{BIBLIOGRAFÍA}

Abad, L.; Cuco, A. y Izquierdo, A. (1993): Inmigración, pluralismo y tolerancia, Editorial Popular, Madrid.

Amin, M. (1999): Identidades asesinas, Alianza Editorial, Madrid.

Bastenier, A. y Dassetto, F. (1979): "Hipothèses pour une analyse des stratégies religieuses au sein du monde migratoire en Europe", SocialCompass, vol. XXVI: 145-170.

Bastian, J. P.; Champion, F. y Rousselet, K. (2001): La globalisation du religieux, L'Harmattan, Paris.

Berger, P. L. (2005): "Pluralismo global y religión", Estudios Públicos, 8: 5-18.

Briones, R.; Castilla, C.; Salguero, 0.; Jiménez, C. y Tarrés, S. (2006): "Incidencia sociocultural de la religión entre los inmigrantes en Andalucia", IV Seminario sobre la investigación de la inmigración extranjera en Andalucía, Junta de Andalucía, Córdoba, pp. 209-223.
Calvo Buezas, T.; Fernández, R. y Rosón, A. G. (1993): Educar para la tolerancia, Editorial Popular, Madrid.

Colectivo IOE (1995): Discursos de los españoles sobre los extranjeros: Paradojas de la alteridad, CIS, Madrid.

Huntington, S. P. (2005): El choque de civilizaciones y la reconfiguración del orden mundial, Paidos, Barcelona.

Llamazares Fernández, D. (2006): “Educación para la ciudadanía, laicidad y enseñanza de la religión", Laicidad y libertades: escritos jurídicos, 6: 219266.

Pérez-Argote, A. y Santiago, J. A. (2005): La situación de la religión en España a principios del siglo XXI, Centro de Investigaciones Sociológicas, Madrid.

Rodríguez Blanco, M. (2005): "La enseñanza de la religión en la escuela pública española (1979-2005)", Observatorio delle Libertà ed Instituzioni Religiose, julio: 1-29.

Satorras Fioretti, R. M. (1998): La libertad de enseñanza en la Constitución Española, Marcial Pons, Madrid.

Tamayo Acosta, J. J. y Fariñas, M. J. (2007): Culturas y religiones en diálogo, Síntesis, Madrid.

Tornos, A.; Aparicio, R. y Labrador, J. (1999): Inmigrantes, integración, religiones. Un estudio sobre el terreno, Universidad Pontificia de Comillas, Madrid. 